\title{
In vitro antioxidant and antimicrobial activity of carotenoid pigment extracted from Sporobolomyces sp. isolated from natural source
}

\section{R. A. Manimala* and R. Murugesan}

Department of Agricultural Microbiology, Tamil Nadu Agricultural University, Coimbatore-641003, (Tamil Nadu), INDIA

*Corresponding author. E-mail: maniarchana20@gmail.com

Received: August 15, 2014; Revised received: September 26, 2014; Accepted: November 13, 2014

Abstract: The aim of the present study was to isolate and study about the antioxidant and antibacterial activity of carotenoid pigment. Sporobolomyces sp. isolated from the phyllosphere surface of rice plant has found to produce carotenoid pigment. The present investigation was carried out for antioxidant assays viz., DPPH, iron reducing and metal chelating activity. A steady increase in the antioxidant activities was observed in the carotenoid pigment with raising the pigment concentration. In the present study, the maximum antioxidation characteristics of carotenoid by $\mathrm{DPPH}$, iron reducing and metal chelating assays $(75.04 \%, 1.88 \%$ and $59.32 \%)$ were achieved by pigmentation of Sporobolomyces sp. at the concentration of $100 \mathrm{\mu g} \mathrm{ml}^{-1}$. The antibacterial activity was studied on several organisms like Enterococcus sp., Staphylococcus aureus, Streptococcus faecalis, Bacillus subtilis, Escherichia coli and Pseudomonas aeruginosa. Among the six pathogens, the pigment was found to be more effective against $E$. coli $(2.9 \mathrm{~cm})$ and $S$. aureus $(2.6 \mathrm{~cm})$. This study revealed that yeast carotenoid pigment was a potential source for its use in food and pharmaceutical applications.

Keywords: Antimicrobial activity, Antioxidant activity, Carotenoid pigment, Sporobolomyces sp.

\section{INTRODUCTION}

Most of the natural pigments are extracted from plants like annatto, beet root, marigold, grapes, carrot, paprika, etc. and microorganisms like yeast of the genera Phaffia, Rhodotorula, Cryptococcus and Sporobolomyces, fungi like Blakeslea trispora, and algae such as Dunaliella and Haematococcus and bacteria such as Flavobacterium and Micrococcus are reported to produce carotenoids. Humans acquire carotenoid pigments through diet, from vegetables and fruits as well as from animal products. In addition to their pigmenting abilities, carotenoids may function as antioxidants by quenching photosentizers, interacting with singlet oxygen, and scavenging peroxy radicals (Frengova et al., 1994). Several studies have shown that carotenoids can be used as therapeutic agents against various type of cancer and other diseases due to their antioxidant and/or provitamin A properties. Secondary metabolites like statins, naphthoquinones and carotenoids produced from micro organism have pharmaceutical applications and possess antimicrobial, antioxidant and anticancer activities (Kumaresan et al., 2008). Microbial carotenoids are of considerable interest in nutrition because of their role as antioxidants and potential for preventing or delaying degenerative diseases and for enhancing immune responses in animals and humans (Kirakosyan et al.,
2003). Carotenoids such as $\beta$-carotene and xanthophylls like astaxanthin play central roles in the metabolism of the eye's macula and retina, maintaining healthy vision and also functions as chemo-protectives (Echavarri and Johnson, 2004).

Antioxidant compounds in food play an important role as a health protecting factor. Scientific evidence suggests that antioxidants reduce the risk for chronic diseases including cancer and heart diseases. The main characteristic of an antioxidant is its ability to trap free radicals. Highly reactive free radicals and oxygen species are present in biological systems from a wide variety of sources. These free radicals may oxidize nucleic acids, proteins; lipid or DNA to initiate regenerative diseases (Kaur et al., 2008). The ability of carotenoids to quench singlet molecular oxygen is well known (Tinkler et al., 1994) and reactions with radical species have also been studied including the prevention of lipid peroxidation (Packer and Cadenas, 2002). Besides cancer prevention, the potential antioxidant properties of carotenoids may help to inhibit the onset of other diseases that are believed to be initiated by free radicals. These include atherosclerosis, cataracts, age-related macular degeneration and multiple sclerosis.

Antibiotic resistant pathogens pose an enormous threat to the treatment of a wide range of serious infections.

To prevent this exponential emergence, a periodic ISSN : 0974-9411 (Print), 2231-5209 (Online) All Rights Reserved @ Applied and Natural Science Foundation www.ansfoundation.org 
replacement of the existing antibiotic is necessary (Llic et al., 2005). Currently, the greatest cause of concern is infection caused by methicilin and vancomycin resistant strains of Staphylococus aureus, ESBL strains of E. coli, Klebsiella sp., and Pseudomonas aeruginosa (Selvameenal et al., 2009). Puspha et al. (2009) reported the antimicrobial activity of total red pigment from Monascus purpureus MTCC 410 recorded more antimicrobial activity, which could yield significant information on the scope for Monascus pigments substituted or as an adjunct to chemotherapeutic agents. Astaxanthin has also health benefits in cardiovascular disease prevention, immune system boosting, bioactivity against Helicobacter pylori, and cataract prevention due to its high antioxidant activity (Kirti et al., 2014). The development of novel drugs against drug resistant pathogen is the need of the hour.

Carotenoids are currently produced for use as nutritional supplements, food colorants, cosmetics or health purposes. Despite the availability of a variety of natural and synthetic carotenoid pigments, there is currently a renewed interest in microbial sources of pigments (Bhosale, 2004). There is growing interest in microbial pigments due to their natural character, medicinal properties and nutritive value. Microbial production being independent of season, geographical conditions, controllable and predictable yield and safety to use (Frengova and Beshkova, 2009). Microbial synthesis offers a promising method for production of carotenoids. This explains the increasing interest in production of microbial carotenoids as alternative for synthetic food colourants. The objective of the present work was to determine the antioxidant and antimicrobial activity of pigment extracted from Sporobolomyces sp. isolated from natural source as a potential role in food and pharmaceutical industry.

\section{MATERIALS AND METHODS}

Study material: The microorganism used in this study was isolated from phyllosphere surface of rice plant collected from wet land, Tamil Nadu Agricultural University, Coimbatore. Stock cultures were maintained on yeast malt extract agar slants at $4^{\circ} \mathrm{C}$ after being incubated at $25-30^{\circ} \mathrm{C}$ for $4-5$ days. The basal medium for liquid culture contained $30.0 \mathrm{~g}$ glucose, $2.5 \mathrm{~g}\left(\mathrm{NH}_{4}\right)$ ${ }_{2} \mathrm{SO}_{4}, 1.0 \mathrm{~g} \mathrm{~K}_{2} \mathrm{HPO} 4,0.5 \mathrm{~g} \mathrm{MgSO}_{4} .7 \mathrm{H}_{2} \mathrm{O}$ and $4.0 \mathrm{~g}$ yeast extract (per litre).

Extraction of carotenoid pigment: The yeast cultures were inoculated on to yeast malt extract broth and incubated at $28 \pm 1^{\circ} \mathrm{C}$ for 5 days. A known amount $(500 \mathrm{mg})$ of freeze-dried red yeast was hydrolyzed with $1 \mathrm{ml}$ of $1 \mathrm{~N}$ hydrochloric acid in water bath at $70^{\circ} \mathrm{C}$ for one and half hour. After removal of excess acid by washing with water, the cells were soaked overnight in acetone: methanol (1:1) solution. The pigment was extracted with acetone until the entire colour was leached out from the cells. Acetone extracts were transferred to light petroleum $(20 \mathrm{ml})$ at $\left(40-60^{\circ} \mathrm{C}\right)$ in a separating funnel and washed thrice with distilled water. The absorbance of the light petroleum phase was documented at $474 \mathrm{~nm}$. The carotenoid yield is reported on the basis of cell mass $\left(\mu \mathrm{g} \mathrm{g}^{-1}\right.$ dried cell weight) (Latha et al., 2005).

Determination of antioxidant activity of yeast carotenoid pigment: Diphenyl-2-picrylhydrazyl (DPPH) scavenging activity (DPPH) assay, reducing power and metal chelating effect were used to determine antioxidant activity of carotenoid produced by Sporobolomyces sp. that was carried out by following standard method of Blois,1958; Benzie and Strain (1996) and Shimada et al.(1992).

Determination of antibacterial activity of yeast carotenoid pigment: Bacterial strain grown in nutrient broth at $37^{\circ} \mathrm{C}$ for $18-24 \mathrm{~h}$ with a load of $10^{8}-10^{9} \mathrm{CFU}$ $\mathrm{ml}^{-1}$. Culture $(100 \mu \mathrm{l})$ was spread on nutrient agar plate by Spread plate method. Using sterile cork borer, a well was formed and impregnated with $100 \mu \mathrm{l}$ of acetone extract of crude pigment. The plates were then incubated at $37^{\circ} \mathrm{C}$ for $24 \mathrm{~h}$. At the end of the incubation period, the susceptibility of the test organism was determined by measuring the zone of inhibition around the well (Iqbal et al., 1998). Hundred $\%$ acetone without the test compound was used as the negative control. The antibacterial agent (Chloramphenicol) at a concentration of $1 \mathrm{mg} \mathrm{ml}^{-1}$ was used as the positive controls.

Test microorganisms: The six human pathogens (bacteria) viz., Enterococcus sp., S. aureus, S. faecalis, B. subtilis, E. coli and P. aeruginosa were used in the study were obtained from the Microbiological Laboratory, Coimbatore, Tamil Nadu, India and $\mathrm{KMCH}$ College of Pharmacy, Coimbatore, Tamil Nadu, India.

\section{RESULTS AND DISCUSSION}

Carotenoid pigment as antioxidants: Carotenoid pigment has the ability to act as antioxidants and thus protect cells against photooxidation. The ability of carotenoids to quench singlet oxygen is well known and reactions with radical species have also been studied (Edge et al., 1997). Dietary carotenoids inhibit onset of many diseases in which free radicals are thought to play a role in initiation, such as atherosclerosis, cataracts, age-related macular degeneration, multiple sclerosis and most importantly cancer (Bhosale, 2004). Michalowska and Stachowiak (2010) reported that highest percentage of DPPH scavenged radicals was recorded in pigment produced from Phaffia rhodozyma for an addition of $0.05 \%$ carotenoid extract $(94.58 \%)$, while the other extracts at different concentrations viz., 0.02 and $0.10 \%$ were slightly weaker scavengers. In the present study, the scavenging activities of DPPH exerted by pigmentation of Sporobolomyces sp. at the concentration of $100 \mu \mathrm{g} \mathrm{ml}^{-1}$ exhibited $75.04 \%$ 
Table 1. DPPH scavenging activity, reducing power activity and metal chelation activity of pigmentation by Sporobolomyces sp.

\begin{tabular}{|c|c|c|c|}
\hline \multirow{2}{*}{$\begin{array}{l}\text { Pigment concentration } \\
\left(\mu \mathrm{g} \mathrm{ml}^{-1}\right)\end{array}$} & \multicolumn{2}{|c|}{ (\% inhibition) } & \multirow[b]{2}{*}{ Metal chelating activity } \\
\hline & DPPH & Reducing power & \\
\hline 20 & $39.51 \pm 0.801$ & $0.99 \pm 0.020$ & $29.64 \pm 0.600$ \\
\hline 40 & $48.39 \pm 1.117$ & $1.56 \pm 0.036$ & $38.21 \pm 0.882$ \\
\hline 60 & $68.33 \pm 1.578$ & $1.78 \pm 0.041$ & $50.91 \pm 1.175$ \\
\hline 100 & $75.04 \pm 1.772$ & $1.88 \pm 0.043$ & $59.32 \pm 1.369$ \\
\hline
\end{tabular}

Table 2. Antibacterial activity of pigment extracted from Sporobolomyces sp. against human bacterial pathogens.

\begin{tabular}{|c|c|c|c|}
\hline \multirow{3}{*}{ Bacterial pathogens } & \multicolumn{3}{|c|}{$\begin{array}{c}\text { Diameter of the inhibition zone }(\mathrm{cm}) \\
\text { Carotenoid pigment producing yeast isolate }\end{array}$} \\
\hline & \multirow{2}{*}{$\begin{array}{c}\text { Pigmentation of } \\
\text { Sporobolomyces sp. }\end{array}$} & \multicolumn{2}{|c|}{ Control } \\
\hline & & PC & $\mathbf{N C}$ \\
\hline \multicolumn{4}{|l|}{ Gram positive } \\
\hline Enterococcus sp. & 1.9 & 1.8 & 0.3 \\
\hline S. aureus & 2.6 & 2.9 & 0.0 \\
\hline S. faecalis & 2.2 & 2.0 & 0.2 \\
\hline B. subtilis & 2.3 & 2.9 & 0.1 \\
\hline \multicolumn{4}{|l|}{ Gram negative } \\
\hline E. coli & 2.9 & 2.8 & 0.1 \\
\hline P. aeruginosa & 2.1 & 2.6 & 0.0 \\
\hline
\end{tabular}

$\mathrm{PC}=$ Positive control (Chloramphenicol) $; \mathrm{NC}=$ Negative control (Acetone) $; \mathrm{NI}=$ No inhibition

inhibition; whereas the standard BHA at the same concentration exhibited $86.44 \%$ inhibition. It gave impression that carotenoid pigment has got the capacity to secrete antioxidants almost equal to BHA.

Likewise the reducing power assay increased as extract concentration increased, indicating that the compounds present in yeast cultures were both electron donors and could react with free radicals and convert them into more stable products to terminate radicals chain interaction. In the present study, all concentrations of Sporobolomyces sp. showed higher activities of iron reducing assays were $0.99,1.56,1.78$ and $1.88 \%$. It could be inferred that antioxidant properties were associated with development of reducing power as described by Tanaka et al. (1998). The reduction of ferric ions is often used as an indicator of electron-donating activity, which is an important mechanism of phenolic antioxidant action and is strongly correlated with other antioxidant properties. Metal chelating activity is an antioxidant mechanism since it mediates transition metal catalysis during lipid peroxidation. In principle it could happen that the ability of carotenoid to inhibit the lipid peroxidation was due to complexing iron in a catalytically silent form (Lloyd et al., 1997). Padmapriya et al., (2014) observed that red pigment produced from Penicillium purpurogenum showed strong $\mathrm{Fe}^{2+}$ chelating activity even at the minimal concentration of $20 \mathrm{mg} \mathrm{ml}^{-1}$ and showed $51.37 \%$ chelating rate. In the present study, pigment extracted from Sporobolomyces sp. showed strong $\mathrm{Fe}^{2+}$ chelating activity at the concentration of $100 \mu \mathrm{g} \mathrm{ml}^{-1}$ and its chelating rate was $59.32 \%$ (Table 1 ). The results suggested that lipid peroxidation inhibitory activity due to combined activity of chain termination by scavenging the peroxy radicals and iron chelation.

Antimicrobial activities of Sporobolomyces sp. carotenoid pigment against human pathogens: Ushakumari and Ramanujam (2013) reported that the astaxanthin pigment was found to be more significantly effective against all tested pathogen species such as $S$. typhi produced (20mm) diameter for zone of inhibition, P. aeroginosa $(24 \mathrm{~mm})$, B. subtilis $(18 \mathrm{~mm})$ and $S$. aureus $(16 \mathrm{~mm})$. Neveen (2011) reported that extracellular pigment of Penicillium purpurogenum was found to be more significantly effective against all tested microbial species which includes Epidermophyton floccosum, Candida albicans, E. coli, P. aeruginosa, S. aureus and B. subtilis. Sanjay (2009) observed that the antimicrobial activity of xanthin pigment at higher concentration of 400 $\mu \mathrm{g} \mathrm{ml}^{-1}$ results in the lysis of pathogenic bacterial cells. In the present study, bacterial pathogen $E$. coli was found to be highly inhibited by the pigment extract of Sporobolomyces sp. with the inhibition zone of $2.8 \mathrm{~cm}$ respectively. This was comparable to the activity of chloramphenicol $(2.8 \mathrm{~cm})$. The carotenoid pigment possessed good activity against $S$. aureus $(2.6 \mathrm{~cm})$. The pathogens like $S$. faecalis and $B$. subtilis were more effectively inhibited by the pigment extract of Sporobolomyces sp. $(2.2$ and $2.3 \mathrm{~cm})$, followed by 
Enterococcus sp. and P. aeruginosa (1.9 and $2.1 \mathrm{~cm})$. The standard antibiotic chloramphenicol produced inhibition zones of 2.9, 2.0, 1.8, 2.8, and $2.6 \mathrm{~cm}$ against $S$. aureus, $S$. faecalis, Enterococcus sp., and E. coli and $P$. aeruginosa accordingly (Table 2). Antibacterial activity showed that there was no uniform response among bacterial strains in terms of susceptibility to pigments. The difference in susceptibility can be attributed to differences in cell wall composition. The reason was referred to the difference in the structures of the cell walls (Singh et al., 2007). Selective antibacterial activity may be due to several factors, including charge density, structure of lipopolysaccharides and lipid composition of the cytoplasmic membrane in Gram-negative and Gram-positive bacteria (Devine and Hancock, 2002). Our results indicated that the chemistry of the pigments has a significant influence on its antimicrobial activity. These results may suggest that the pigment might be developed as antibiotic drug.

\section{Conclusion}

Invitro study using carotenoid pigment extracted from the yeast Sporobolomyces sp. apart from its use as food colourant also showed antioxidant and antimicrobial property. Under invitro assay condition pigment efficiently scavenged free radicals from DPPH, showed strong $\mathrm{Fe}^{2+}$ chelating and reducing power activity exhibited 77.18, 59.32 and $1.88 \%$ inhibition at the concentration of $100 \mu \mathrm{g} \mathrm{ml}^{-1}$. The antibacterial activity of pigment showed significant inhibitory activity against pathogenic bacterial strains. Pigment was found to exhibit excellent inhibitory effect against $E$. coli $(2.9 \mathrm{~cm})$ and $S$. aureus $(2.6 \mathrm{~cm})$. Thus the carotenoid pigment may be potential source for use in food and pharmaceutical applications. Since none had attempted so far, current study would be the pioneering report for determining the better antioxidant and antimicrobial activity of the yeast Sporobolomyces sp.

\section{ACKNOWLEDGEMENT}

The authors greatly acknowledge the Indian council of Agricultural Research (ICAR) for the financial support granted under the scheme "Application of microorganisms in Agriculture and allied sciences (AMAAS)" to carry out this study.

\section{REFERENCES}

Benzie, I.F. and Strain, J.J. (1996). The ferric reducing ability of plasma (FRAP) as a measure of antioxidant power: the FRAP assay. Analytical biochemistry, 239: 70-76

Bhosale, P. (2004). Environmental and cultural stimulants in the production of carotenoids from microorganisms. Applied Microbiology and Biotechnology, 63: 351361.

Blois, M.S. (1958). Antioxidant determinations by the use of a stable free radical. Nature, 29: 1199-1200

Devine, D.A. and Hancock, R.E. (2002). Cationic peptides, distribution and mechanisms of resistance. Current
Pharmaceutical, 8: 703-714.

Echavarri, E.C. and Johnson, E.A. (2004). Stimulation of astaxanthin formation in the yeast Xanthophyllomyces dendrorhous by the fungus Epicoccum nigrum. FEMS Yeast Research, 4: 511-519.

Edge, R., Mcgarvey, D.J. and Truscott, T.G. ( 1997). The carotenoids as antioxidants: A review. Journal of Photochemistry and Photobiology, 41: 189-200.

Frengova, G., Simova, E., Pavlova, K., Beshkova, D. and Grigorora, D. (1994). Formation of carotenoids by Rhodotorula glutinis in whey ultrafiltrate. Biotechnology and Bioengineering, 44: 888-894.

Frengova, G. and Beshkova, M. (2009). Carotenoids from Rhodotorula and Phaffia: yeasts of biotechnological importance. J ournal of Industrial Microbiolology and Biotechnology, 36(2):163-180.

Iqbal, A., Zafar, M. and Faiz, M. (1998). Screening of some medicinal plants for their antimicrobial activities. Journal of Ethnopharmacology, 62: 183-193.

Kaur, R., Arora, S. and Singh, B. (2008). Antioxidant activity of the phenol rich fractions of leaves of Chukrasia tabularis A. Juss. Bioresource Technology, 99: 7682-7698.

Kirakosyan, A., Seymour, E., Kaufman, O.B., Warber, S., Bolling, S. and Chang, S.C. (2003). Antioxidant capacity of polyphenolic extracts from leaves of Crataegus laevigata and Crataegus monogyna (Hawthorn) subjected to drought and cold stress. Journal of Agricultural and Food Chemistry, 51: 3973 $-3976$.

Kirti, K., Amita, S., Priti, S., Mukesh Kumar, A. and Jyoti, S. (2014). Colorful world of microbes: carotenoids and their applications. Advances in Biology: 1-13.

Kumaresan, N., Sanjay, K.R., Venkatesh, K.S., Kadeppagari, R.K., Vijaylakshmi, G. and Kumar, S.U. (2008). Partially saturated canthaxanthin purified from Aspergillus carbonarius induces apoptosis in prostate cancer cell line. Applied Microbiology and Biotechnology, 80: 467-473.

Latha, B., Jeevaratnam, Murali, H.S. and Manja, K.S. (2005). Influence of growth factors on carotenoid pigmentation of Rhodotorula glutinis DFR-PDY from natural source. Indian Journal of Biotechnology, 4:353 $-357$.

Llic, S.B., Kontantinovic, S.S. and Todorovic, Z.B. (2005). UV-vis analysis and antimicrobial activity of Streptomyces isolates. Medicine and Biology, 121: 4446.

Lloyd, R.V., Hanna, P.M. and Mason, R.P. (1997). The origin of the hydroxyl radical oxygen in the fenton reaction. Free Radical Biology and Medicine, 22(5): 885888 .

Michalowska, A.G. and Stachowiak, B. (2010). The antioxidant potential of carotenoid extract from Phaffia rhodozyma. Acta Scientiarum Polonorum Technologia Aliment, 9(2):171-188.

Neveen, S.G. (2011). Investigation of the optimum condition and antimicrobial activities of pigments from four potent pigment-producing fungal species. Journal of Life Sciences, 5: 697-711.

Packer, L. and Cadenas, E. (2002). Hand Book of Antioxidants. In: Carotenoids: Antioxidant and other properties of green tea and black tea. Marcel Dekker, Inc., New York. pp. 372.

Padmapriya, C., Murugesan, R. and Gunasekaran, S.(2014). 
In vitro antioxidant and antibacterial studies of fungal pigment extracts from Parambikulam tiger reserve. Trends in Bioscience, 7(13): 1522-1557.

Puspha, S.M., Vanajakshi, V. and Vijayalakshmi, G. (2009). Antimicrobial activity of ployketides of Monascus purureus. Asian Journal of Microbiolology Biotechnology and Environmental Sciences, 9(2): 225-229.

Sanjay, K.R. (2009). Characterization of Aspergillus carbonarius mutant in relation to xanthin production toxicity studies and fermentation conditions for pigment production. Ph.d Degree, CFTRI, Mysore.

Selvameenal, L., Radhakrishnan, M. and Balagurunathan, R. (2009). Antibiotic pigment from desert soil actinomycetes; biological activity, purification and chemical screening. International Journal of Pharmaceutical sciences, 4: 499 - 504.

Shimada, K., Fujikawa, K. Yahara, K. and Nakamura, T. (1992). Antioxidative properties of xanthan on the autoxidation of soybean oil in cyclodextrin emulsion.
Journal of agricultural and Food Chemistry, 40: 945948.

Singh, D., Ramesh, K. Vandna, M. and Parikshit, T. (2007). Synthesis and characterization of complexes of cyclohexadeca-6, 8, 14, 16-tetraene and their biological screening. Transition Metal Chemistry, 32: 1051-1055.

Tanaka, M., Kuei, C.W., Nagashima, Y. and Taguchi, T. (1998). Application of antioxidative maillrad reaction products from histidine and glucose to sardine products. Nippon Suisan Gakkaishi, 54(1): 1409-1414.

Tinkler, J. H., F. Biihm, W. Schalch and T.G. Truscott. (1994). Dietary carotenoids protect human cells from damage. Journal of Photochemistry and Photobiology, 26: 283-285.

Ushakumari,U. and Ramanujan, R. (2013). Isolation of astaxanthin from marine yeast and study of its pharmacological activity. International Current Pharmaceutical Journal, 2(3): 67-69. 